\title{
A Comparative Study on Physical Fitness among National Cadet Corps and Non-National Cadet Corps Adolescent College Girls
}

\author{
P. Charishma ${ }^{1}$, Navaneetha $\mathbf{R}^{2}$ \\ ${ }^{1}$ M.Sc. Food and Nutrition, Department of Food and Nutrition and Research Centre, \\ Smt.V.H.D Central Institute of Home Science Seshadri Road Bengaluru - 560001 \\ ${ }^{2}$ Associate Professor, Department of Food and Nutrition and Research Centre, \\ Smt.V.H.D Central Institute of Home Science Seshadri Road Bengaluru - 560001 \\ Corresponding Author: Navaneetha R
}

DOI: https://doi.org/10.52403/ijhsr.20220237

\begin{abstract}
Physical fitness and health of young students is of great importance for the progress and prosperity of the nation. Lack of regular exercise and improper life style choices can lead to various ailments like obesity, hypertension, early onset diabetes and various metabolic syndromes. Indians are at an increased risk of heart ailments at a much younger age when compared to western population. The present study was carried out on 60 adolescent girls (17-19 years) of Maharani Women's Arts, Commerce and Management College Bengaluru. The study compared physical fitness and anthropometric data of the students who were undergoing National Cadet Corps (NCC) training (experimental) and students who did not undergo NCC training (control group). The students were selected by purposive sampling. Health related fitness tests and anthropometric measurements were administered in 2 trials. The results showed the following: underweight was $47 \%$ amongst the experimental group with mean and SD $(18.91 \pm 2.37)$. Underweight was $40 \%$ with mean and S.D of $(19.23 \pm 2.19)$ in the control group. Waist hip ratio of control and experimental group was in the range of 0.75-0.79. The experimental group showed excellent physical fitness level when compared to the control group. Significant difference was observed in the performance of sit ups, pushups and 3 minute step test at $1 \%$ level of significance between the control and experimental subjects.

This study shows that there is need for introducing regular exercises to increase physical fitness amongst adolescents.
\end{abstract}

Key Words: physical fitness, National Cadet Corps, adolescents, anthropometry

\section{INTRODUCTION}

Physical activity and nutrition play a significant role in this formative period of adolescence. Healthy lifestyle during this period is likely to continue into their adulthood. Life style diseases like diabetes, hypertension, obesity etc. are major causes leading to increased global burden of disease. By 2030 life style diseases are expected to cause $70 \%$ of deaths globally. /1/
Health of the population is directly related to the economic growth of the nation by increased labor productivity $/ 2 /$. According to World Health Organization children between 10-19 years of age are referred as adolescents. Adolescence is the transitional phase from a child to an adult and is associated with physical, sexual, psychological and social changes in an individual. 13/. Life style diseases can be largely prevented by maintaining a healthy weight, regular exercise and by cultivating 
healthy eating habits. Public health initiatives should emphasize the importance of physical activity in promoting good health. Adolescents are the future citizens of the nation and their physical fitness is essential for the well being of the nation. /4/

The present study compared physical fitness and anthropometric data of adolescent students (17-19 Years) who were undergoing National Cadet Corps (NCC) training (experimental) and students who did not undergo NCC training (control group). Research has shown that in the recent times, there is a clear decrease in physical activity, among adolescence girls. Therefore, adolescent girls have been identified as a key target population./7/

\section{METHODS AND MATERIALS}

Anthropometric parameters and health related physical fitness components were assessed and compared among 60 college going adolescent girls, 30 students who were not involved in any physical activity and 30 who were undergoing regular NCC training at maharani women's college, Bangalore.

Anthropometric measurements of the participants were taken by using standard procedures. Health related physical fitness components tests were administered in two trails among the respondents to determine their physical fitness with necessary equipments. Body mass index (BMI) was calculated (weight on $\mathrm{Kg}$ / Height in $\mathrm{m}^{2}$ ) to classify the participants into under weight, overweight or obese according to WHO classification

The physical fitness was assessed by using four health related fitness components, they are: Cardiovascular endurance was assessed by using Harvard step test (A. W. Sloan 1959). Muscular endurance was measured by using 1 minute sit ups test, (Maria H. Diener et al - 1995). Muscular strength was measured by using 1minute pushups test (Ted A. Baumgartner et al- 2002). Flexibility was measured by using Toe-Touch Test (Vauqhan Kippers et al - 1987). All the analysis was done by using T test.181

\section{RESULT}

Table - 1: Comparison of Anthropometric Measurements of NCC and Non NCC Adolescent Girls

\begin{tabular}{|l|l|l|l|l|l|l|}
\hline \multirow{2}{*}{ Anthropometric Measurements } & \multirow{2}{*}{ Number } & \multicolumn{2}{l}{ NCC (Experimental group) } & \multicolumn{2}{l|}{ Non NCC(Control group) } & \multirow{2}{*}{ Significance of t value } \\
\cline { 3 - 7 } & & Mean & SD & Mean & SD & \\
\hline Height & 30 & 158.57 & 5.06 & 158.40 & 4.31 & $0.1401^{\text {NS }}$ \\
\hline Weight & 30 & 47.13 & 6.53 & 47.20 & 6.36 & $0.0420^{\text {NS }}$ \\
\hline BMI & 30 & 18.91 & 2.37 & 19.23 & 2.19 & $0.5434^{\text {NS }}$ \\
\hline Waist Circumference & 30 & 69.57 & 5.57 & 69.20 & 9.43 & $0.1851^{\text {NS }}$ \\
\hline Hip Circumference & 30 & 88.22 & 5.75 & 88.87 & 5.44 & $0.4500^{\text {NS }}$ \\
\hline W/H Ratio & 30 & 0.78 & 0.09 & 0.77 & 0.08 & $0.4566^{\mathrm{NS}}$ \\
\hline
\end{tabular}

The above table indicates the comparison of mean levels of anthropometric measurements of the respondents. Anthropometric measurements is a good indicator of long term nutritional status. The control group (Non - NCC adolescent girls) showed a mean height of $158.4 \mathrm{~cm}$ and S.D. (4.31) when compared to the experimental group (NCC adolescent girls) whose mean height was $158.57 \mathrm{~cm}$ and S.D.(5.06). No significant difference was observed ( $t$ value -0.1401$)$ in height of both control and experimental group.
Weight determines the short term nutritional status and an indicator of current nutritional status of an individual. The control group (Non - NCC adolescent girls) showed a mean weight of $47.2 \mathrm{~kg}$ and S.D. (6.36) when compared to the experimental group (NCC adolescent girls) whose mean weight was $47.13 \mathrm{~kg}$ and S.D.(6.53). No significant difference was observed ( $t$ value -0.0420 ) in weight of both control and experimental group.

BMI determines the health status of an individual. The control group (Non - 
NCC adolescent girls) showed a mean BMI of $19.23 \mathrm{~kg} / \mathrm{m}^{2}$ and S.D. (2.19) when compared to the experimental group (NCC adolescent girls) whose mean BMI was $18.91 \mathrm{~kg} / \mathrm{m}^{2}$ and S.D (2..37). No significant difference was observed ( $t$ value -0.5434 ) in BMI of both control and experimental group.

Waist circumference is an indicator of health risk associated with excess fat around the waist. The control group (Non NCC adolescent girls) showed a mean waist circumference of $69.2 \mathrm{~cm}$ and S.D. (9.43) and mean hip circumference of $88.87 \mathrm{~cm}$ and S.D (5.44) when compared to the experimental group (NCC adolescent girls) whose mean waist circumference was 69.57 $\mathrm{cm}$ and S.D (5.57), mean hip circumference of $88.22 \mathrm{~cm}$ and S.D (5.75). No significant difference was observed (waist circumference $t$ value - 0.5434),(hip circumference $t$ value -0.4500 ) in waist and hip circumference of both control and experimental group.

The Waist Hip Ratio (WHR) has been used as an indicator or measure of health, and the risk of developing serious health conditions. The control group (Non NCC adolescent girls) showed a mean WHR of 0.77 and S.D. (0.08) when compared to the experimental group (NCC adolescent girls) whose mean WHR was 0.78 and S.D (0.09). No significant difference was observed ( $t$ value -0.4566 ) in WHR of both control and experimental group.

Table -2: Comparison of BMI according to standards among NCC and Non NCC students

\begin{tabular}{|l|l|l|l|l|l|}
\hline \multirow{2}{*}{ BMI class } & \multicolumn{2}{|l|}{ NCC (Experimental group) } & Non NCC(Control group) & Significance of Chi square \\
\cline { 2 - 5 } & Number & Percentage & Number & Percentage & \\
\hline $\begin{array}{l}\text { Under weight } \\
<18.5\end{array}$ & 14 & 47 & 12 & 40 & \multirow{2}{*}{$0.4461^{\mathrm{NS}}$} \\
\hline $\begin{array}{l}\text { Normal } \\
18.5-22.9\end{array}$ & 13 & 43 & 16 & 53 & \\
\hline $\begin{array}{l}\text { Pre-overweight } \\
23.0-24.9\end{array}$ & 3 & 10 & 2 & 7 & \\
\hline Total & 30 & 100 & 30 & 100 & \\
\hline
\end{tabular}

The above table reveals the level of BMI as per classification among the subjects. Among the control group (Non NCC adolescent girls) $40 \%$ of them are underweight, $53 \%$ of them have normal BMI, and lowest $7 \%$ of them were pre overweight and there was no obesity among the girls. Among the experimental group
(NCC adolescent girls) $47 \%$ of them are underweight, $43 \%$ of them have normal BMI, and lowest $10 \%$ of them are pre - over weight and there was no obesity in both the groups. The majority of control group was having normal BMI, and in the experimental group majority are under weight.

Table - 3: Correlation among Anthropometric Measurements of NCC Adolescent Girls
\begin{tabular}{|l|l|l|l|l|}
\hline Correlation & Height & Weight & Waist C & Hip C \\
\hline Height & 1.0000 & & & \\
\hline Weight & $0.3104^{\mathrm{NS}}$ & 1.0000 & & \\
\hline Waist C & $-0.2672^{\mathrm{NS}}$ & $0.3692^{*}$ & 1.0000 & \\
\hline Hip C & $0.2008^{\mathrm{NS}}$ & $0.6120^{* *}$ & $0.1395^{\mathrm{NS}}$ & 1.0000 \\
\hline
\end{tabular}
Significant at 1\% level * Significant at 5\% level NS Not significant

The above table reveals the Correlation among Anthropometric Measurements of experimental group (NCC Adolescent Girls) at $1 \%$ and $5 \%$ level of significance. At $1 \%$ level there is a significant difference of (0.612) on weight and hip circumference of NCC adolescent girls. At 5\% level there is a significant difference of (0.369) on weight and waist circumference of NCC adolescent girls. No significant difference is identified among other categories. 
P. Charishma et.al. A comparative study on physical fitness among national cadet corps and non-national cadet corps adolescent college girls.

Table 4: Correlation among Anthropometric Measurements of Non NCC Adolescent Girls

\begin{tabular}{|l|l|l|l|l|}
\hline Correlation & Height & Weight & Waist C & Hip C \\
\hline Height & 1.0000 & & & \\
\hline Weight & $0.3506^{\mathrm{NS}}$ & 1.0000 & & \\
\hline Waist C & $0.0936^{\mathrm{NS}}$ & $0.8202^{* *}$ & 1.0000 & \\
\hline Hip C & $0.2608^{\mathrm{NS}}$ & $0.7699^{* *}$ & $0.7089^{* *}$ & 1.0000 \\
\hline
\end{tabular}

The above table reveals the Correlation among Anthropometric Measurements of control group (Non NCC Adolescent Girls) at $1 \%$ level of significance. A significant difference of (0.7699) on weight and hip circumference, also 0.8202 on weight and waist circumference and about 0.7089 on hip circumference and waist circumference of Non - NCC adolescent girls at $1 \%$ level of significance was observed. No significant difference is identified among other categories.

Table - 5: Comparison of Physical Fitness Test among NCC and Non NCC Adolescent Girls

\begin{tabular}{|c|c|c|c|c|c|c|}
\hline \multirow[t]{2}{*}{ Physical Fitness } & \multirow[t]{2}{*}{ Number } & \multicolumn{2}{|c|}{$\begin{array}{l}\text { NCC } \\
\text { (Experimental group) }\end{array}$} & \multicolumn{2}{|c|}{$\begin{array}{l}\text { Non NCC } \\
\text { (Control group) }\end{array}$} & \multirow[t]{2}{*}{ Significance of $t$ value } \\
\hline & & Mean & SD & Mean & SD & \\
\hline Cardiovascular 3 Min step test & 30 & 80.62 & 9.57 & 88.28 & 8.88 & $2.1139 *$ \\
\hline Strength push ups & 30 & 64.95 & 10.27 & 41.15 & 12.05 & $8.2375 * *$ \\
\hline Endurance sit ups & 30 & 22.30 & 5.66 & 13.27 & 5.87 & $6.0685 * *$ \\
\hline Flexibility - standing flex & 30 & 21.87 & 7.52 & 25.53 & 16.06 & $1.1310^{\mathrm{NS}}$ \\
\hline
\end{tabular}

Table 5 shows the comparison of Physical fitness among NCC and Non NCC Adolescent Girls. Among experimental group (NCC adolescent girls) the cardiovascular test (3 Min step test) with mean score of 80.62, S.D - 9.57, muscle strength test (push up) with mean 64.95, S.D -10.27 , muscle endurance test (sit ups) with mean of 22.3 and S.D 5.66, and flexibility test (standing flex) with mean 21.87 and S.D 7.52 and control group (NCC adolescent girls) the cardiovascular test (3 Min step test) with mean score of 88.28 , S.D - 8.88, muscle strength test (push up) with mean 41.15, S.D - 12.05, muscle endurance test (sit ups) with mean of 13.27 and S.D 5.87, and flexibility test (standing flex) with mean 25.53 and S.D 16.06. The cardiovascular tests are significantly different from the controls ( $t$ value $2.1139)$ at $5 \%$ level of significance. The muscle strength tests are significantly different from the controls ( $t$ value $8.2375)$ at $1 \%$ level of significance. The muscle endurance tests are significantly different from the controls ( $t$ value $6.0685)$ at $1 \%$ level of significance. No significant difference was observed in flexibility tests of the experimental group and control group.

\section{CONCLUSION}

Regular exercise along with good nutrition plays an important role in maintaining health of an individual at all stages of life. In the recent times people are getting used to a sedentary life and an increased consumption of junk food. Sedentary life style coupled with increased consumption of highly processed foods are leading to the development of various lifestyle diseases. Adolescents are usually more conscious about their body image. It was observed that considerable majority of adolescents concentrate on excessive physical exercises or resort to extremes methods of dieting. Both the above factors can lead to both short term and long term adverse health outcomes.

Correlation of weight and hip circumference of NCC girls when compared to the control group showed significant difference both at $1 \%(0.612)$ and at $5 \%$ (0.369). The majority of waist hip ratio of control group and experimental group are in the range of $0.75-0.7$ which is considered good and acceptable according to standard 
guidelines. When physical fitness among NCC and non NCC adolescents were analysed the following was observed: cardiovascular tests showed significant difference from the controls ( $t$ value 2.1139) at $5 \%$ level of significance, muscle strength tests showed a significant difference at $1 \%$ ( $\mathrm{t}$ value 8.2375) endurance tests were significantly different from the controls $(\mathrm{t}$ value 6.0685 ) at $1 \%$ level of significance. NCC girls performed better in all physical fitness tests like cardiovascular tests, muscle strength and endurance tests. Structured physical activity goes a long way in maintaining the health of the adolescents. NCC aims at developing character, comradeship, discipline, a secular outlook and nationalistic feelings in the youngsters.

\section{Acknowledgement: None}

\section{Conflict of Interest: None}

\section{Source of Funding: None}

\section{REFERENCES}

1. Fatma Al-Maskari, "Lifestyle Diseases: An Economic Burden on the Health Services", the magazine of the United Nations Vol. XLVII No. 22010.

2. Adolescent Nutrition: A Review of the Situation in Selected South-East Asian Countries.

WHO. https://apps.who.int/iris/bitstream/handle/1 0665/204764/B0239.pdf;jsessionid=7BDF 5BE23ECD9204380E32A7401C7A3B?seq uence $=1$
3. Financing the future Choices and challenges in global health. A report from the Economist Intelligence Unit - 2015

4. Manmeet Gill, Nishan Singh Deol \& Ramanjit Kaur (2010) Comparative Study of Physical Fitness Components of Rural and Urban Female Students of Punjabi University, Patiala, The Anthropologist, 12:1, 17-21, DOI: $10.1080 / 09720073.2010 .11891126$

5. National Institute of Nutrition, 1998.

6. Zaqout M, Michels N, Bammann K, Ahrens W, Sprengeler O, Molnar D, Hadjigeorgiou C, Eiben G, Konstabel K, Russo P, JiménezPavón D, Moreno LA, De Henauw SInt J Obes (Lond). 2016 Influence of physical fitness on cardio-metabolic risk factors in European children. The IDEFICS study, International journal of obesity 40(7):111925.

7. Jitendra Amberkar and Dr. Vishwambhar Jadhav, "Muscular endurance of students: A comparison of NCC cadets, yoga practitioners and sports persons", International Journal of Yogic, Human Movement and Sports Sciences 2021; 6(1): 107-108.

8. Kippers, Vaughan \& Parker, Anthony. (1987). Toe-Touch Test A Measure of Its Validity. Physical therapy. 67. 1680-1684. 10.1093/ptj/67.11.1680.

How to cite this article: P. Charishma, Navaneetha R. A comparative study on physical fitness among national cadet corps and nonnational cadet corps adolescent college girls. Int J Health Sci Res. 2022; 12(2): 266-270. DOI: https://doi.org/10.52403/ijhsr.20220237 